\title{
Design of a Low-Cost Easy-to-Fly STOL Ultralight Aircraft in Composite Material
}

\author{
D. P. Coiro, A. de Marco, F. Nicolosi, N. Genito, S. Figliolia
}

The paper deals with the design of an aircraft, starting from a market survey, the conceptual design loop and the preliminary choice of dimensions, and leading to the detailed design of efficient high-lift systems and a low-drag fuselage shape. Technological challenges regarding the design of low-cost systems for flap/slat retraction and a simple wing folding system are highlighted. Aiming at an efficient optimization algorithm, we developed a new integration technique between CAD, aerodynamic and structural numerical calculation. Examples deriving from this new approach are presented.

Keywords: STOL, preliminary design.

\section{Notation}

AR Wing aspect ratio.

$C_{\text {Lmax }} \quad$ Maximum Lift coefficient of the aircraft with retracted flaps.

$C_{\mathrm{LmaxFF}} \quad$ Maximum Lift coefficient of the aircraft with full flaps.

$C_{\text {LmaxL }}$ Maximum Landing Lift coefficient of the aircraft.

$C_{\text {LmaxTO }}$ Maximum Take Off Lift coefficient of the aircraft.

$R C, R C_{\max }$ Maximum Rate of Climb.

$S \quad$ Wing area.

$S_{\mathrm{LG}}, S_{\mathrm{TOG}}$ Landing Ground run, Take Off Ground run.

$t \quad$ Time.

$t_{\text {min }} \quad$ Minimum time of climb to altitude $\mathrm{z}$.

$V\left(R C_{\max }\right) \quad$ Speed at maximum Rate of Climb.

$V_{\text {max }}, V_{\text {min }}$ Maximum level speed, minimum level speed.

$V_{\mathrm{s}}, V_{\mathrm{sFF}} \quad$ Stalling speed flaps up, stalling speed flapsdown.

$W_{\mathrm{E}} \quad$ Empty Weight.

$W_{\text {TO }} \quad$ Maximum Take Off Weight.

$P \quad$ Power.

z Altitude.

$\rho, \rho_{0} \quad$ Density, density at sea level.

\section{Introduction}

The class of Ultralight (ULM) and light aircraft in general has attracted by growing interest through Europe in recent years. Only in Italy in the last 5-6 years, at least 10 companies have started production of ULM aircraft. There is a very active market for this class, used to promote flight at all levels and for sports aircraft The maximum flight speed for ULM aircraft has been increased in recent years through the use of more powerful engines (100 hp instead of 64 or 80 ) and better aerodynamics. It is not surprising that a maximum level speed of about $280 \mathrm{~km} / \mathrm{h}$ has been reached. Since the weight constraints are very strict, it is important to study ways to improve structural design, safety, flight qualities, aeroelastic behaviour and systems reliability, without raising costs.. Following the experience acquired in our department in designing light and ultralight aircraft, the design of a new composite ULM is being carried out at DPA. The design goals established for this new design were: 1) Short Take-Off and Landing (STOL) aircraft capable of taking off and landing from an uprepared runway within $40 \mathrm{~m}$; 2) almost complete construction in composite material; 3) foldable wing, in order to make the ULM very easy to use, to put on a trailer and to hangar in a normal size garage; 4) wing with a retractable leading edge slat and slotted/fowler flaps; 5) maximum speed around $190-200 \mathrm{~km} / \mathrm{h}$ at MTOW of $450 \mathrm{~kg}$; 6) good flight and handling qualities, to be safely flown by inexperienced pilots; 7) low cost.

\section{Market survey}

All the analyzed aircraft are ULM $\left(\mathrm{W}_{\mathrm{TO}}=450 \mathrm{~kg}=\right.$ $4415 \mathrm{~N})$ and equipped with an $80 \mathrm{hp}(59.6 \mathrm{~kW})$ engine; most of them are made of aluminium alloy with a high wing configuration, ensuring high stability and easy piloting. None satisfies all the above-mentioned design goals. In fact, the YUMA, the Savannah and the Zenair CH 701 are successful STOL aircraft made of aluminium alloy; however, their de-

Table 1: Weights, sizes and performances at sea level of the analyzed aircraft (M. - Material: a - aluminium alloy, c - composite; W.p. Wing position: $\mathrm{h}$ - high, $\mathrm{l}$ - low.)

\begin{tabular}{|c|c|c|c|c|c|c|c|c|c|c|c|c|c|c|c|}
\hline Aircraft & M. & W.p. & $\begin{array}{c}W_{\mathbf{E}} \\
{[\mathrm{N}]}\end{array}$ & $\frac{W_{\mathbf{E}}}{W_{\text {TO }}}$ & $\begin{array}{l}\frac{W_{\text {TO }}}{S} \\
{\left[\mathrm{~N} / \mathrm{m}^{2}\right]}\end{array}$ & $\begin{array}{c}S \\
{\left[\mathrm{~m}^{2}\right]}\end{array}$ & $A R$ & $\begin{array}{c}V_{\mathbf{S}} \\
{[\mathrm{km} / \mathrm{h}]}\end{array}$ & {$\left[\begin{array}{c}\boldsymbol{V}_{\mathbf{S F F}} \\
{[\mathrm{km} / \mathrm{h}]}\end{array}\right.$} & $\begin{array}{c}\boldsymbol{V}_{\mathbf{m a x}} \\
{[\mathrm{km} / \mathrm{h}]}\end{array}$ & $\begin{array}{c}\boldsymbol{R} \boldsymbol{C} \\
{[\mathrm{m} / \mathrm{s}]}\end{array}$ & $\begin{array}{c}S_{\text {TOG }} \\
{[\mathrm{m}]}\end{array}$ & $\begin{array}{l}S_{\mathbf{L G}} \\
{[\mathrm{m}]}\end{array}$ & $C_{\mathrm{Lmax}}$ & $C_{\mathrm{LmaxFF}}$ \\
\hline P92 ECHO 80 & $\mathrm{a}$ & $\mathrm{h}$ & 2757 & 0.62 & 334.43 & 13.20 & 6.55 & 71 & 61 & 210 & 5.5 & 110 & 100 & 1.40 & 1.90 \\
\hline P96 GOLF 80 & $\mathrm{a}$ & 1 & 2757 & 0.62 & 361.84 & 12.20 & 5.78 & 71 & 61 & 225 & 4.5 & 110 & 100 & 1.52 & 2.06 \\
\hline
\end{tabular}




\begin{tabular}{|c|c|c|c|c|c|c|c|c|c|c|c|c|c|c|c|}
\hline Aircraft & M. & W.p. & $\begin{array}{l}W_{\mathbf{E}} \\
{[\mathrm{N}]}\end{array}$ & $\frac{W_{\mathbf{E}}}{W_{\mathrm{TO}}}$ & $\begin{array}{c}\frac{W_{\mathrm{TO}}}{S} \\
{\left[\mathrm{~N} / \mathrm{m}^{2}\right]}\end{array}$ & $\begin{array}{c}S \\
{\left[\mathrm{~m}^{2}\right]}\end{array}$ & $A R$ & $\begin{array}{c}\boldsymbol{V}_{\mathbf{S}} \\
{[\mathrm{km} / \mathrm{h}]}\end{array}$ & $\begin{array}{c}\boldsymbol{V}_{\mathbf{S F F}} \\
{[\mathrm{km} / \mathrm{h}]}\end{array}$ & $\begin{array}{c}V_{\max } \\
{[\mathrm{km} / \mathrm{h}]}\end{array}$ & $\begin{array}{c}\boldsymbol{R C} \\
{[\mathrm{m} / \mathrm{s}]}\end{array}$ & $\begin{array}{c}S_{\text {TOG }} \\
{[\mathrm{m}]}\end{array}$ & $\begin{array}{l}S_{\mathbf{L G}} \\
{[\mathrm{m}]}\end{array}$ & $C_{\mathrm{Lmax}}$ & $C_{\mathrm{LmaxFF}}$ \\
\hline REMOS G-3 & c & $\mathrm{h}$ & 2757 & 0.62 & 366.65 & 12.04 & 7.98 & 75 & 63 & 220 & 6.5 & 80 & 140 & 1.38 & 1.95 \\
\hline DF 2000 & $\mathrm{a}$ & $\mathrm{h}$ & 2747 & 0.62 & 367.88 & 12.00 & 8.33 & 66 & 56 & 215 & 5.5 & 110 & 100 & 1.79 & 2.48 \\
\hline YUMA (STOL) & $\mathrm{a}$ & $\mathrm{h}$ & 2766 & 0.63 & 328.46 & 13.44 & 7.07 & 55 & 50 & 175 & 6.0 & 40 & 55 & 2.30 & 2.78 \\
\hline $\begin{array}{l}\text { SAVANNAH } \\
\text { (STOL) }\end{array}$ & $\mathrm{a}$ & $\mathrm{h}$ & 2668 & 0.60 & 343.81 & 12.84 & 6.28 & 50 & 45 & 160 & 6.0 & 50 & 50 & 2.91 & 3.59 \\
\hline $\begin{array}{l}\text { ZENAIR CH } 701 \\
\text { (STOL) }\end{array}$ & $\mathrm{a}$ & $\mathrm{h}$ & 2580 & 0.58 & 387.24 & 11.40 & 5.90 & 53 & 48 & 153 & 7.0 & 50 & 50 & 2.92 & 3.56 \\
\hline AMIGO! & $\mathrm{a}$ & 1 & 2806 & 0.64 & 339.58 & 13.00 & 5.24 & 74 & 64 & 250 & 6.5 & 80 & 100 & 1.31 & 1.75 \\
\hline $\begin{array}{l}\text { SLEPCEV } \\
\text { STORCH Mk4 } \\
\text { (STOL) }\end{array}$ & $\mathrm{a}$ & $\mathrm{h}$ & 2649 & 0.60 & 275.91 & 16.00 & 6.76 & 52 & 46 & 155 & 4.5 & 50 & 50 & 2.16 & 2.76 \\
\hline $\begin{array}{l}\text { SKY ARROW } \\
450 \mathrm{~T}\end{array}$ & c & $\mathrm{h}$ & 2825 & 0.64 & 326.76 & 13.51 & 6.96 & 70 & 61 & 192 & 5.1 & 120 & 80 & 1.41 & 1.86 \\
\hline Allegro 2000 & $\mathrm{a}$ & $\mathrm{h}$ & 2727 & 0.62 & 387.24 & 11.40 & 10.23 & 73 & 63 & 220 & 5.0 & 150 & 100 & 1.54 & 2.06 \\
\hline $\begin{array}{l}\text { SINUS } 912 \\
\text { Motoaliante }\end{array}$ & c & $\mathrm{h}$ & 2786 & 0.63 & 360.07 & 12.26 & 18.28 & 66 & 63 & 220 & 6.5 & 88 & 100 & 1.75 & 1.92 \\
\hline AVIO J-Jabiru & c & $\mathrm{h}$ & 2649 & 0.60 & 474.17 & 9.31 & 9.49 & 74 & 64 & 216 & 6.0 & 100 & 160 & 1.83 & 2.45 \\
\hline $\begin{array}{l}\text { EV-97 EURO } \\
\text { STAR Model } \\
2001\end{array}$ & $\mathrm{a}$ & 1 & 2570 & 0.58 & 448.63 & 9.84 & 6.67 & 75 & 65 & 225 & 5.5 & 125 & 90 & 1.69 & 2.25 \\
\hline JET FOX 97 & a, c & $\mathrm{h}$ & 2845 & 0.64 & 301.95 & 14.62 & 6.54 & 70 & 60 & 175 & 6.0 & 100 & 120 & 1.30 & 1.77 \\
\hline TL 96 Star & $\mathrm{a}$ & 1 & 2747 & 0.62 & 364.83 & 12.10 & 6.87 & 80 & 63 & 250 & 6.0 & 90 & 100 & 1.21 & 1.94 \\
\hline
\end{tabular}

sign is unattractive, and they have a fixed slat on the leading edge, which reduces maximum cruising speed. The Sky Arrow $450 \mathrm{~T}$ and the REMOS G-3, on the contrary, are high cost "non-STOL" aircraft in composite materials, advanced ULM. They can easily by put onto a trailer, due to their removable or foldable wing. The main characteristics of the analyzed aircraft are shown in Table 1. Their main performance charac- teristics in terms of landing run versus maximum level speed at sea level are shown in Fig. 1.

\section{Design point}

The methodology followed during the design process is similar to that reported in [1], but it has been expressly modi-

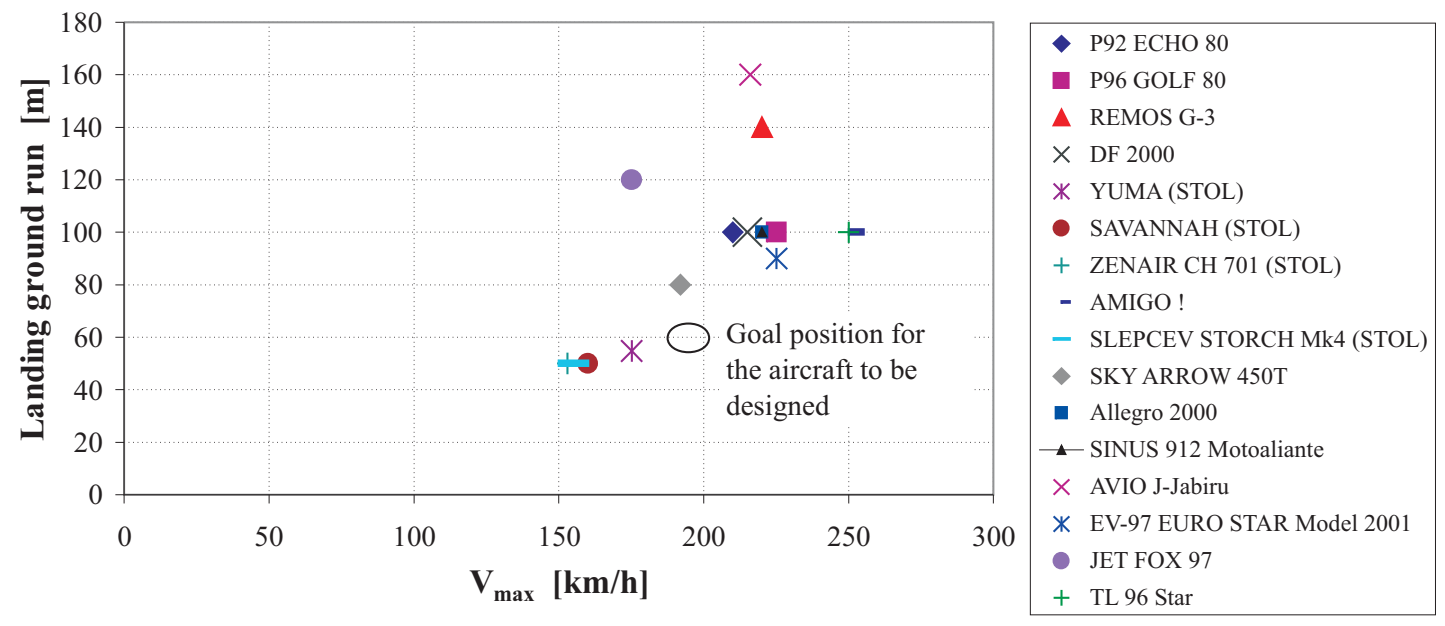

Fig. 1: Landing ground run versus maximum level speed at sea level 
fied for the ULM category: in particular, new statistical relations between take off ground run $\mathrm{S}_{\mathrm{TOG}}$ and Take Off Pa-

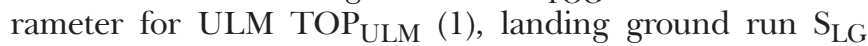
and landing stall speed $V_{S L}$, power index Ip (3) and maximum speed at sea level $\mathrm{V}_{\text {max }}$ have been calculated, as shown in Figs. 2, 3 and 4. TOP ${ }_{\mathrm{ULM}}$ is defined as:

$$
\mathrm{TOP}_{\mathrm{ULM}}=\frac{\left(\frac{W}{P}\right)_{\mathrm{TO}}\left(\frac{W}{S}\right)_{\mathrm{TO}}}{\sigma \cdot C_{\mathrm{L} \max \mathrm{TO}}} ;
$$

with $\left(\frac{W}{S}\right)_{\mathrm{TO}}$ in $\left[\mathrm{N} / \mathrm{m}^{2}\right]$ and $\left(\frac{W}{P}\right)_{\mathrm{TO}}$ in $[\mathrm{N} / \mathrm{W}]$;

$$
\sigma=\frac{\rho}{\rho_{0}} .
$$

Ip is defined as:

$$
I p=\sqrt[3]{\frac{\frac{W}{S}}{\left(\frac{W}{P}\right)_{\mathrm{cr}}}}
$$

with $\frac{W}{S}$ in [psf] and $\left(\frac{W}{P}\right)_{\mathrm{cr}}$ in $[\mathrm{lbs} / \mathrm{hp}]$;

$$
P_{\mathrm{cr}}=k z * k v * \varphi * P_{\mathrm{TO}} .
$$

In (4) $P_{\mathrm{cr}}$ and $P_{\mathrm{TO}}$ are respectively the power at cruising and take off, $k v$ and $k z$ are the speed and altitude factor (for a four-stroke engine $k v=1$ and $\left.k z=\sigma^{1.22}\right), \varphi$ is the engine admission limit. The data scattering is probably due to limited reliability of the published data, and due to an unbiased difficulty in measuring the data: for example, slight differences in executed manouvres lead to great differences in measured data.

For this STOL aircraft, the main restrictions are maximum speed, take off and landing run, as shown in Fig. 5. Once these limitations have been reported in a graph relating power loading $(W / P)_{\mathrm{TO}}$ and wing loading $(W / S)_{\mathrm{TO}}$, the resulting shaded area represents all the possible design point choices. Maximum power loading is fixed $\left((W / P)_{\mathrm{TO}}=74 \mathrm{~N} / \mathrm{kW}\right)$, because maximum take off weight $(450 \mathrm{~kg}=4415 \mathrm{~N})$ and power $(80 \mathrm{hp}=59.6 \mathrm{~kW})$ have been fixed. In this way only maximum wing loading has been

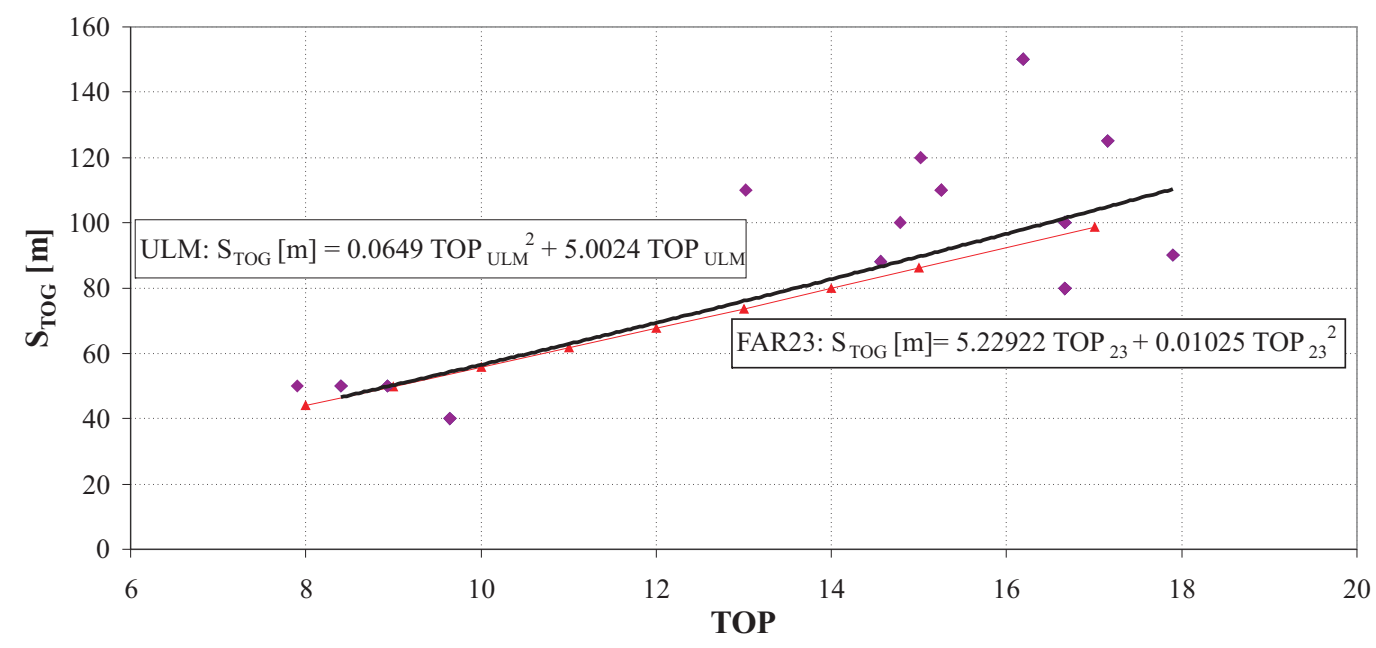

Fig. 2: Take off ground run $S_{\text {TOG }}$ versus take off parameter TOP

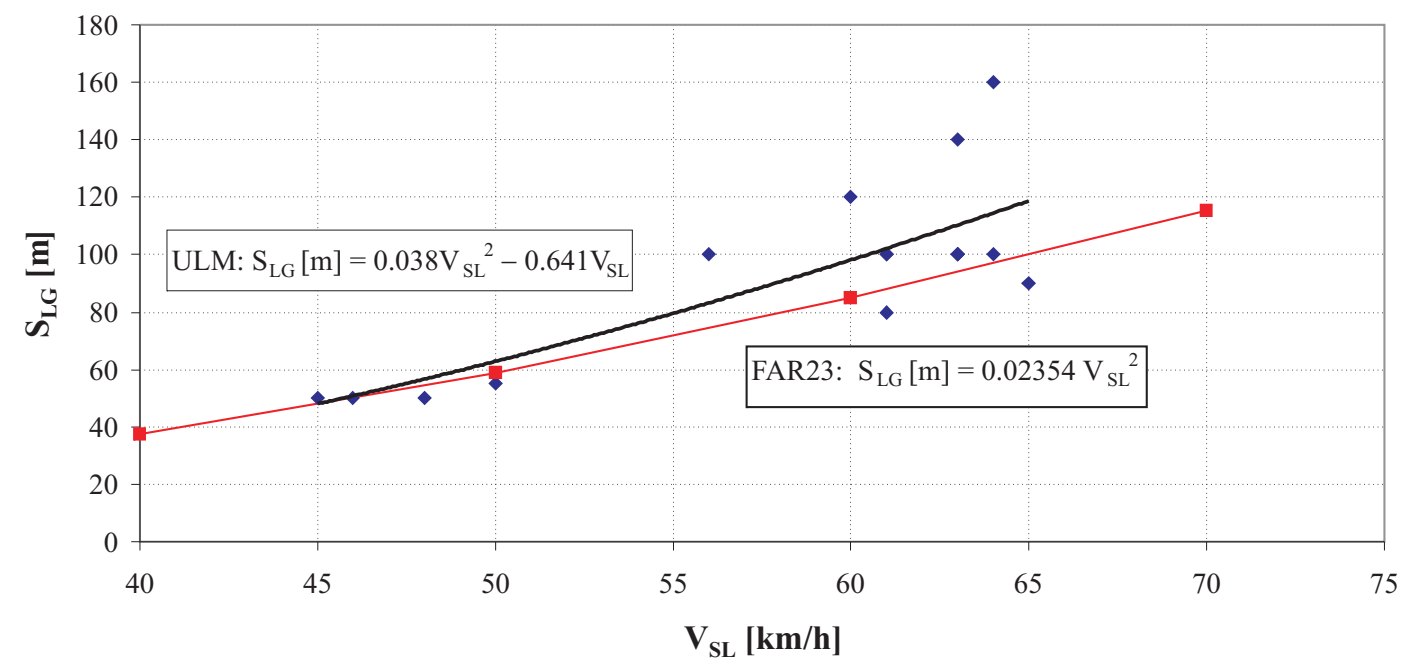

Fig. 3: Landing ground run $S_{\mathrm{LG}}$ versus landing stall speed at sea level $V_{\mathrm{SL}}$ 


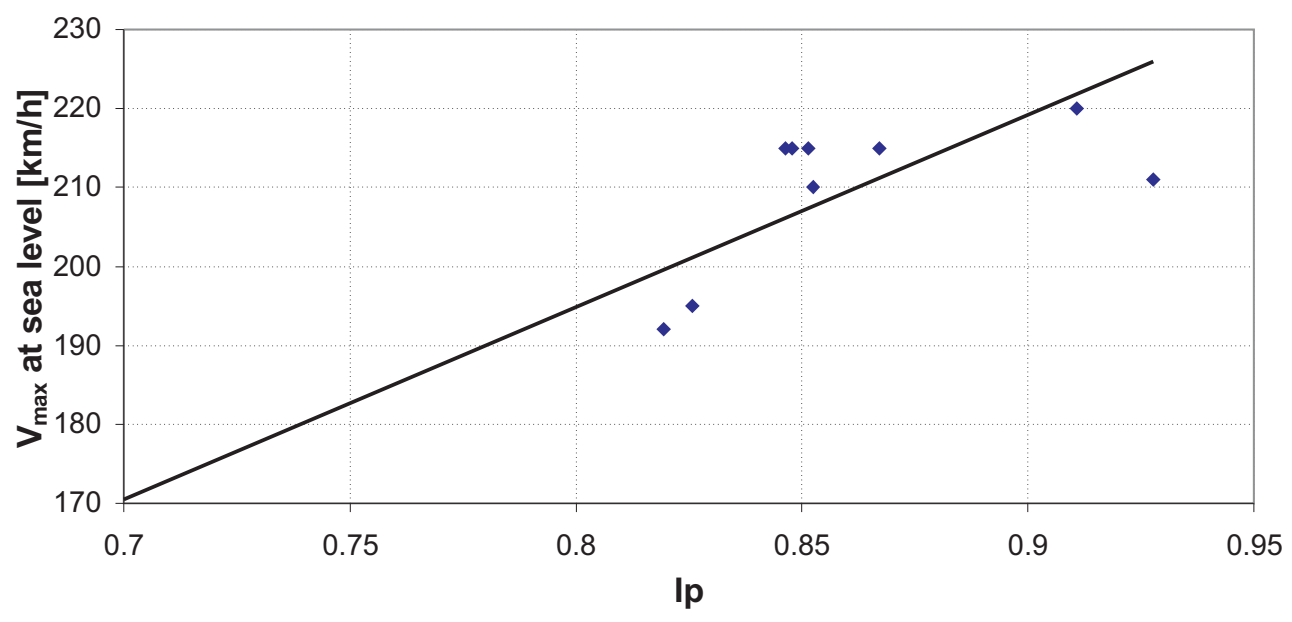

Fig. 4: Maximum speed $V_{\max }$ versus power index $I p$

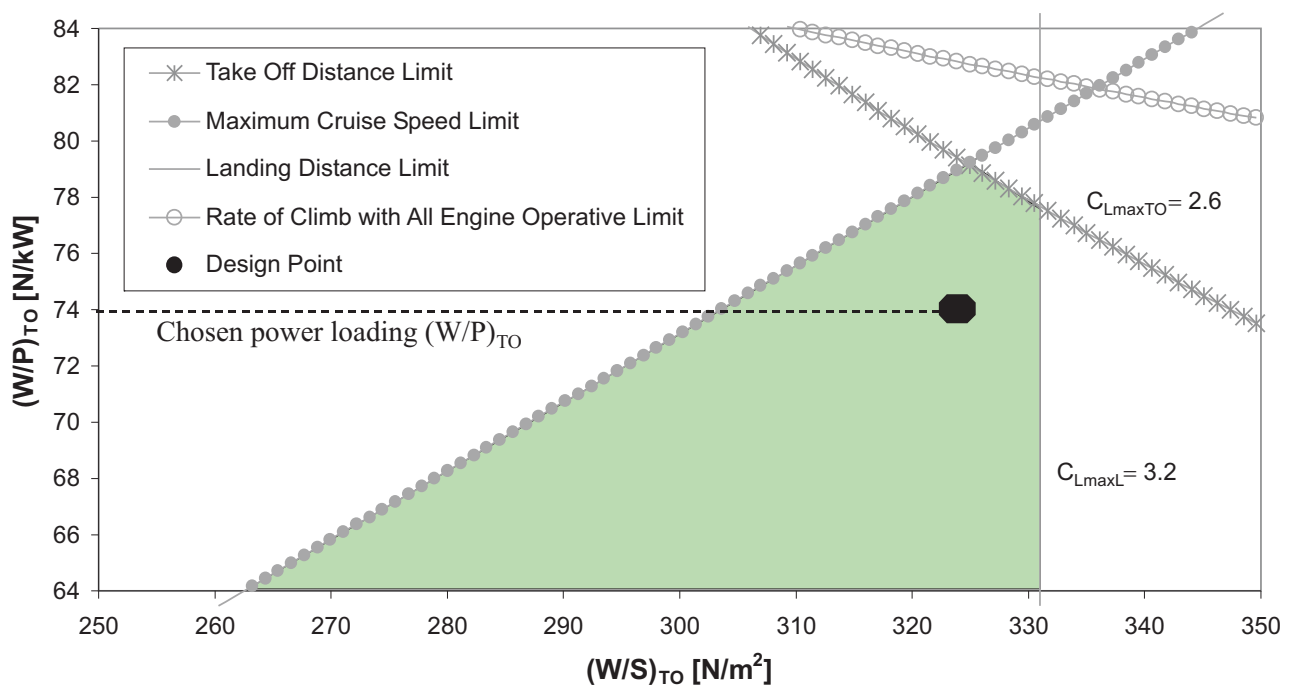

Fig. 5: Maximum power loading $(\mathrm{W} / \mathrm{P})_{\mathrm{TO}}$ versus maximum wing loading $(\mathrm{W} / \mathrm{S})_{\mathrm{TO}}$

chosen, based on the criteria for keeping the wing area as small as possible (mainly for cost reasons) and using appropriate values of maximum take off and landing lift coefficient $\left((W / S)_{\mathrm{TO}}=324 \mathrm{~N} / \mathrm{m}^{2}, S=13.6 \mathrm{~m}^{2}, C_{\mathrm{LmaxTO}}=2.45\right.$, $\left.C_{\text {LmaxL }}=3.12\right)$.

\section{Preliminary design}

The conceptual loop is shown in Fig. 6. It looks simple, but, for example, converting the geometry of sections into CAD geometry is a complicated and delicate step: aircraft

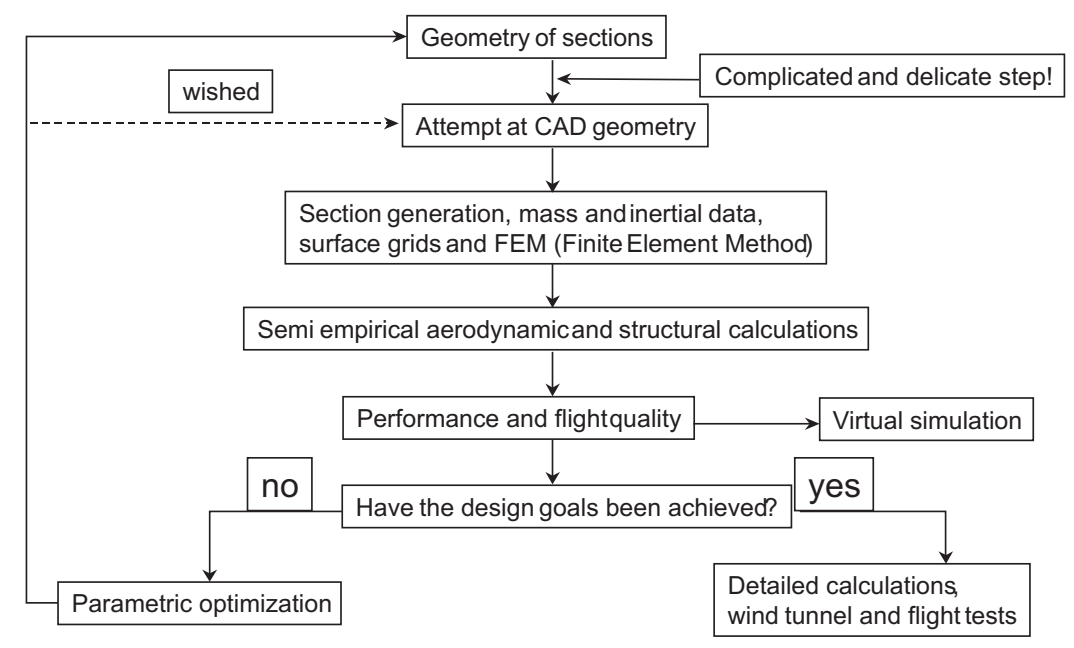

Fig. 6: Conceptual loop design 


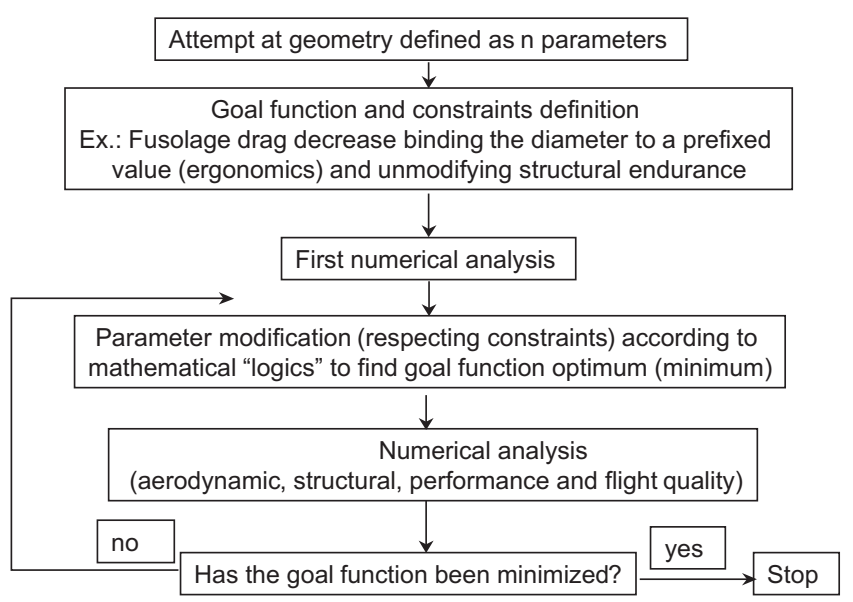

Fig. 7: Parametric optimization loop

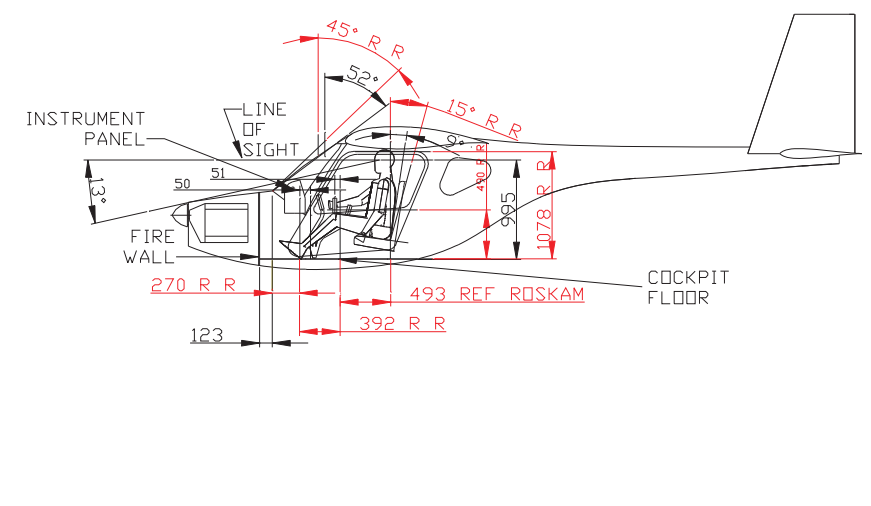

Fig. 9: Ergonomics and line of sight of the fuselage

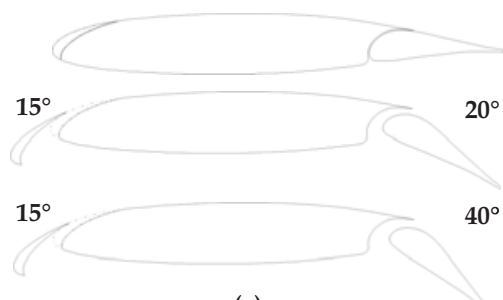

(a) $20^{\circ}$

$40^{\circ}$

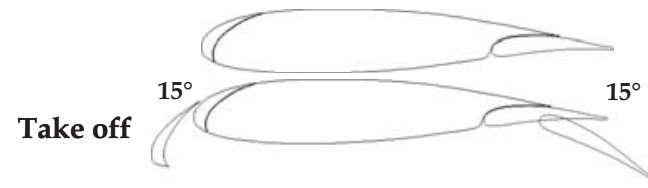

Landing

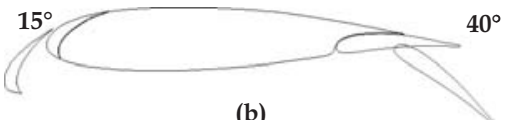

(b)

Fig. 8: Possible high lift system configurations: (a) slat - single slot; (b) slat - fowler

surfaces must be carefully defined, otherwise the aircraft geometry will be different from the desired design. The parametric optimization loop is shown in Fig. 7. First of all, the preliminary geometry was fixed, analyzing existing aircraft and applying semi-empirical methods. The wing was sized to minimize the required power at cruising speed. Some airfoils were analyzed and a new airfoil was designed (modifying NACA GAW1 airfoil) to provide a compromise between lift, drag and pitch moment coefficients. The high lift system and aileron sizing ensures the STOL characteristic and good lat- eral control; this has been demonstrated by J. Roskam [2], W. McCormick [3], C. D. Perkins and R. E. Hage [4] and by the authors [5]. In particular, two possible high lift system configurations are shown in Fig. 8. The horizontal and vertical tails were sized by the volume method, ensuring good stability and control also in landing. The fuselage design is very important and it was based on aerodynamic, ergonomic and line of sight studies, as shown in Fig. 9. A 3-view of the aircraft is shown in Fig. 10; Table 2 reports the main dimensions, weights and loadings.
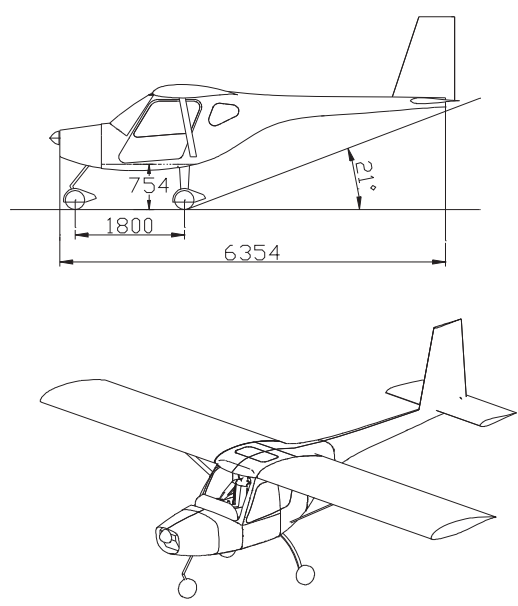
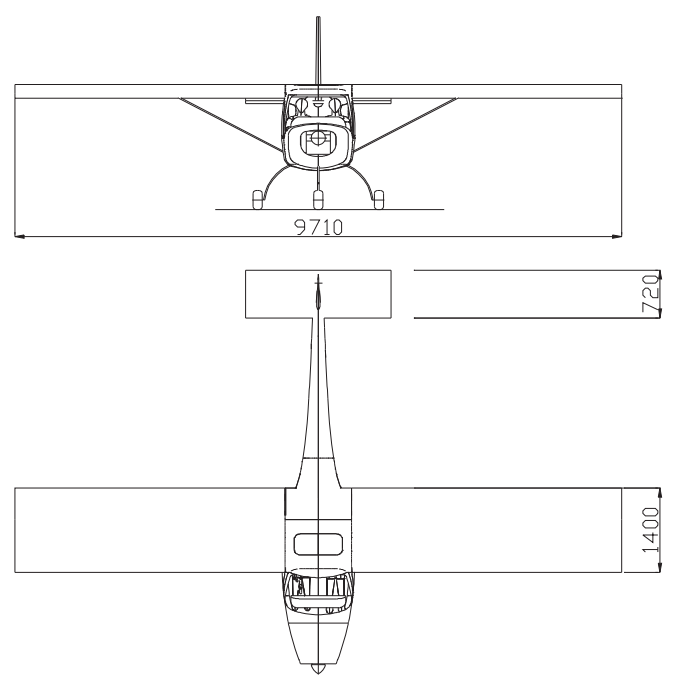

Fig. 10: 3-view of the aircraft 
Table 2: Main dimensions, weights and loadings

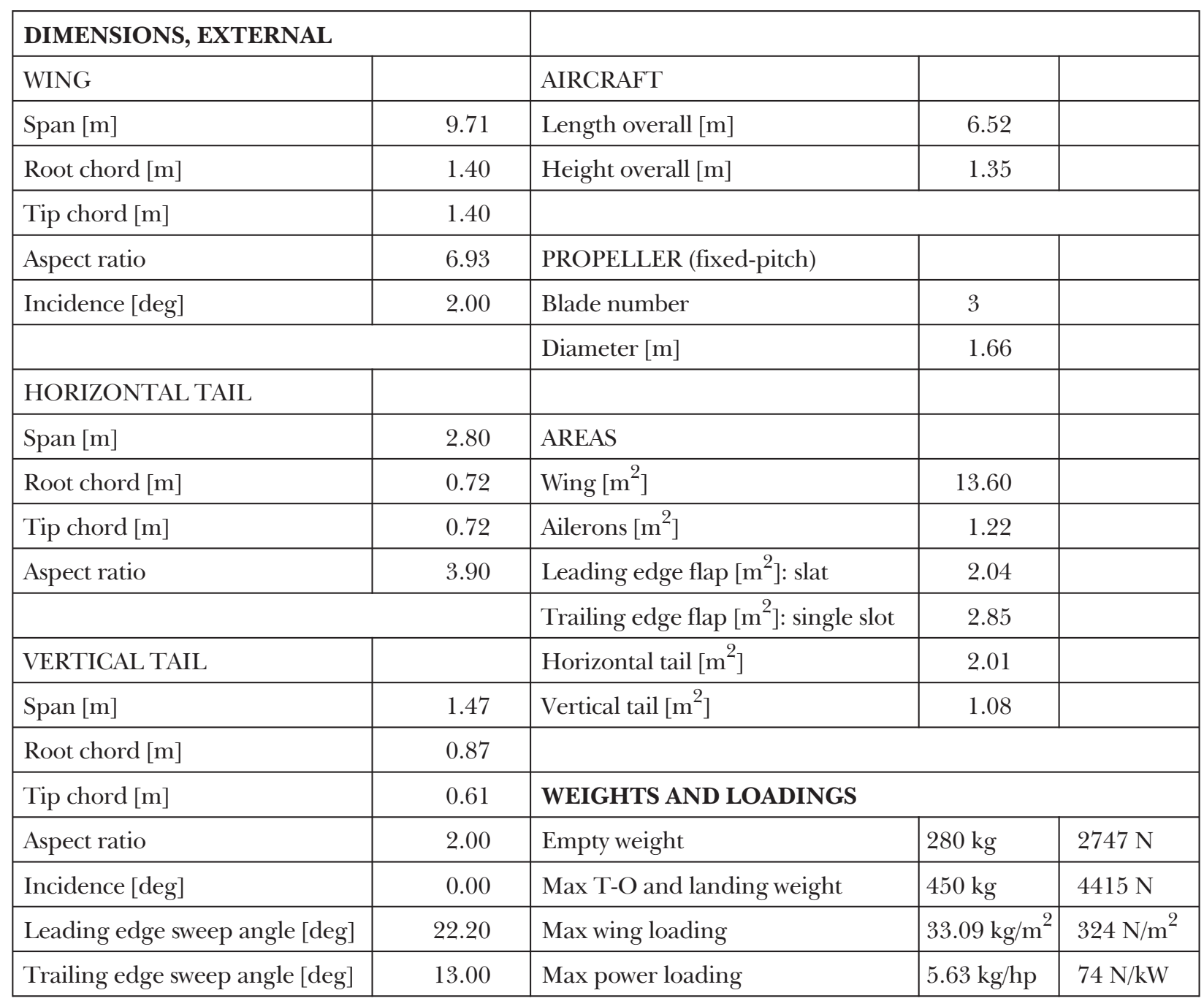

\section{Numerical analysis}

The design was accomplished using a code named AEREO [5], which has been developed in recent years at DPA to predict all aerodynamic characteristics in linear and non-linear conditions (high angles of attack) and all flight performances as well as dynamic behavior and flight qualities of propeller driven aircraft. The figures below report some aerodynamic characteristics (Figs. 11, 12, 13 and 14) and performance characteristics (Fig. 15) of the aircraft calculated with AEREO code. Table 3 reports the main performances of the aircraft. Further optimization of the global configuration is in progress to improve the wing aero-structural behavior as well as the relative position of the wing and horizontal tail to minimize downwash and induced drag.

Table 3: Performances

\begin{tabular}{|l|c|l|c|}
\hline \multicolumn{5}{|l|}{ PERFORMANCE (Max weight, ISA, at sea level) } \\
\hline Max speed $[\mathrm{km} / \mathrm{h}]$ & 194 & Take off run to $15 \mathrm{~m}[\mathrm{~m}]$ & 121 \\
\hline Cruising speed $[\mathrm{km} / \mathrm{h}]$ & 165 & Landing run from $15 \mathrm{~m}[\mathrm{~m}]$ & 100 \\
\hline Stall speed $[\mathrm{km} / \mathrm{h}]$ : flaps up & 65 & Landing run $[\mathrm{m}]$ & 50 \\
\hline flaps down: slat - single slot & 48 & Theoretical ceiling $[\mathrm{m}]$ & 7908 \\
\hline Max rate of climb $[\mathrm{m} / \mathrm{s}]$ & 6.69 & Service ceiling $[\mathrm{m}]$ & 7317 \\
\hline Take off run $[\mathrm{m}]$ & 55 & & \\
\hline
\end{tabular}




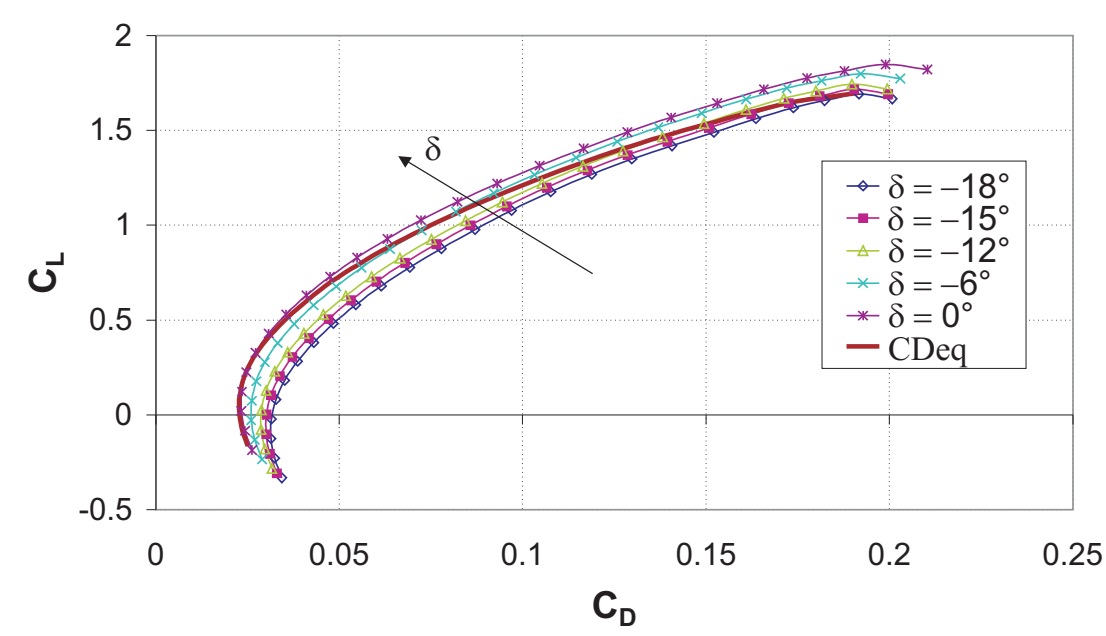

Fig. 11: Polar curves parameterized in d (horizontal all-movable tail deflection) and equilibrium polar curve

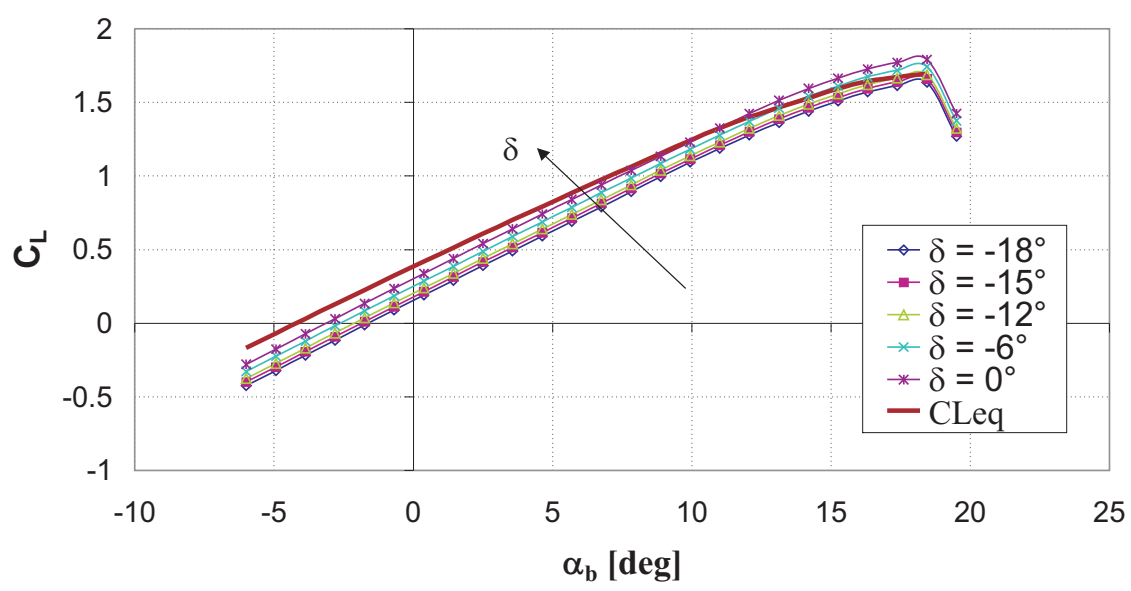

Fig. 12: Lift coefficient of the aircraft versus alpha body (incidence angle measured in regard to the thrust axis) parameterized in $\delta$ (horizontal all-movable tail deflection) and equilibrium lift coefficient

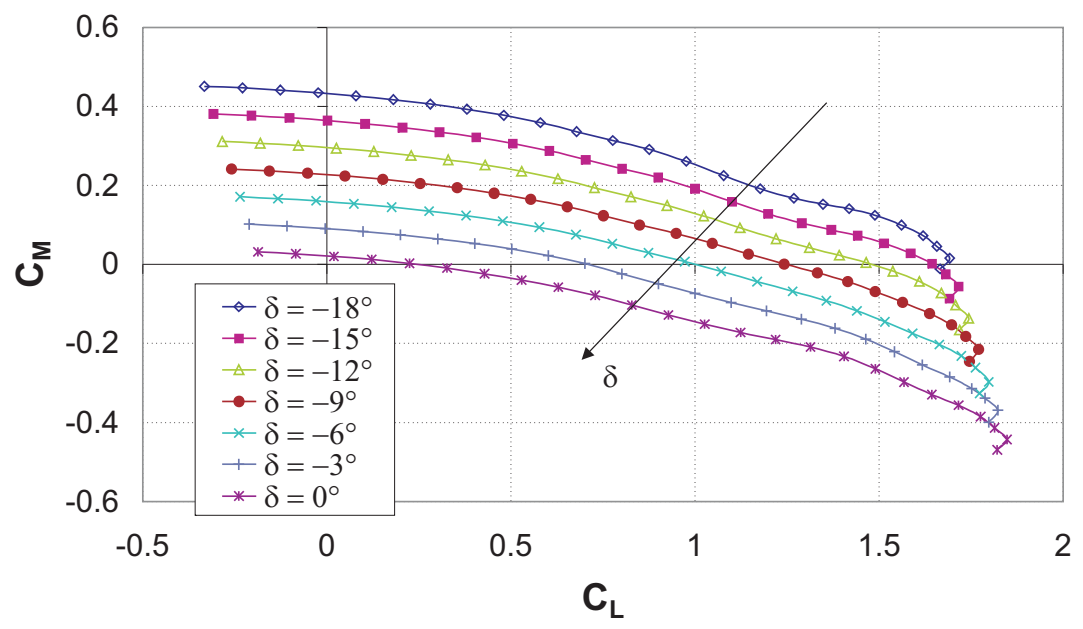

Fig. 13: Pitch moment coefficient versus lift coefficient parameterized in $\delta$ (horizontal all-movable tail deflection)

\section{Conclusion}

The preliminary design of a STOL ULM aircraft and numerical performance prediction has been shown. The aircraft shows acceptable performances that are consistent with the desired design goals. The predicted performances were ob- tained with AEREO code, which confirmed its usefulness as a fast and reliable design tool for propeller-driven aircraft. The parametric design and optimization loops have been highlighted. Detailed design and optimization of the high-lift system and three-dimensional aerodynamic analysis are in progress, while wind tunnel tests (high-lift airfoil, aircraft model) are planned in the near future. 


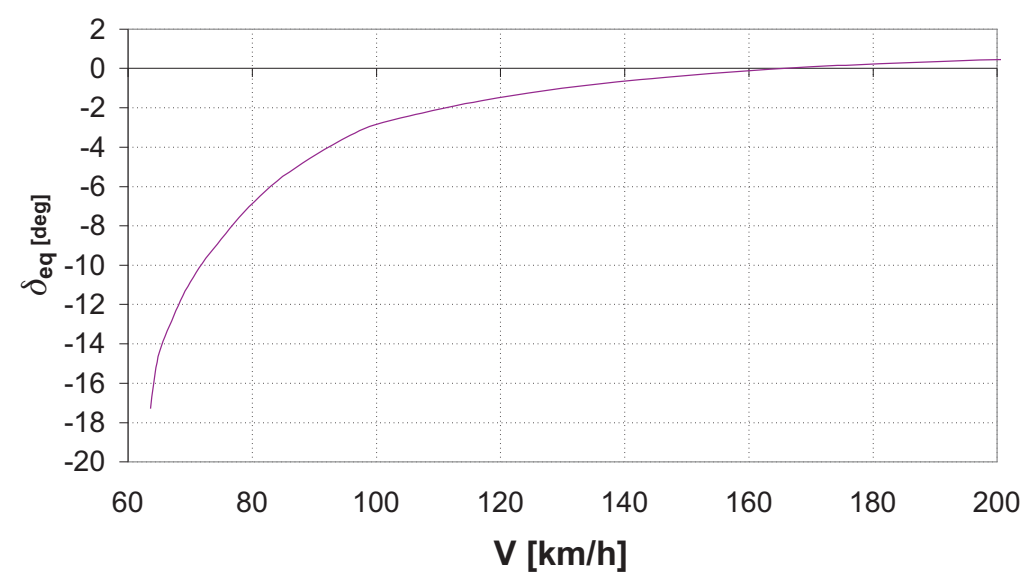

Fig. 14: Equilibrium horizontal all-movable tail deflection versus speed (center of gravity position is at $25 \%$ of mean aerodynamic chord)

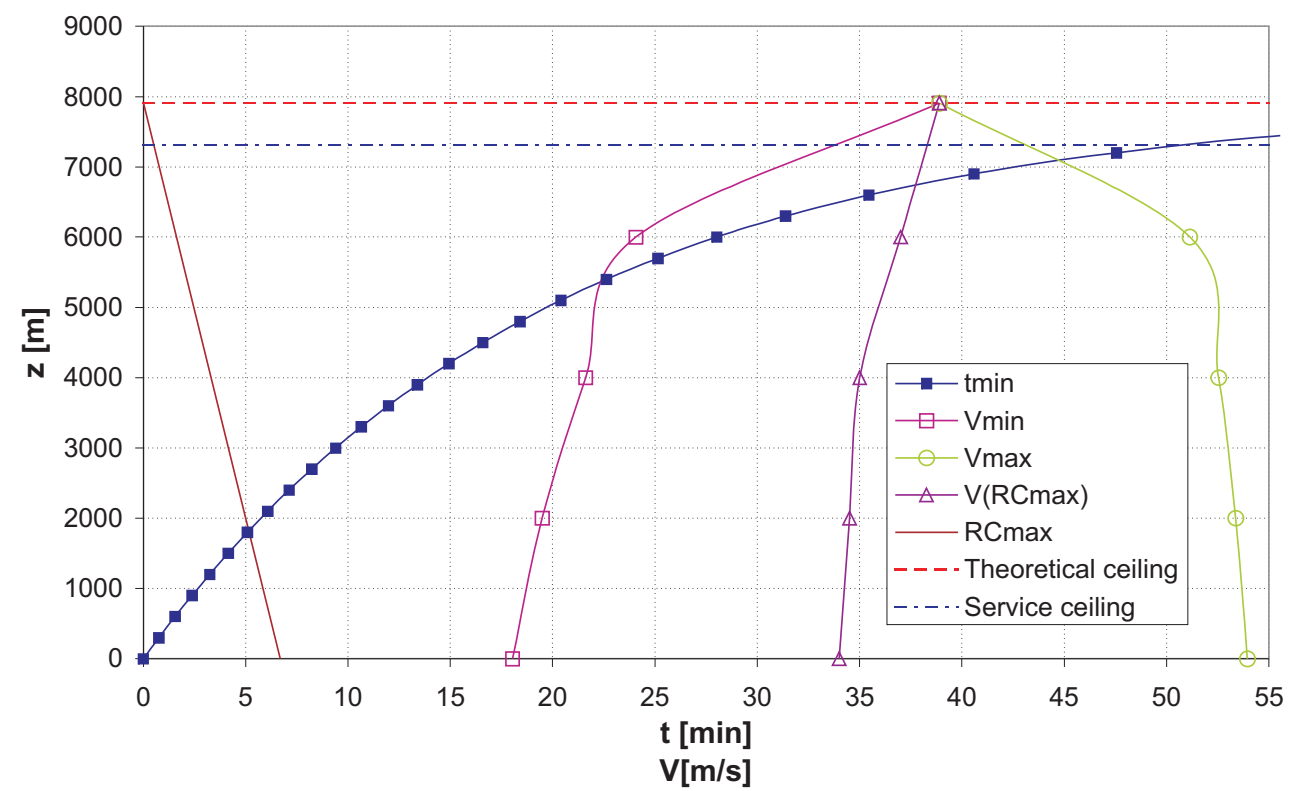

Fig. 15: Flight envelope

\section{References}

[1] Roskam, J.: Part I: Preliminary Sizing of Airplanes. Lawrence, Kansas 66044, U.S.A.: 120 East $9^{\text {th }}$ Street, Suite 2, DARcorporation, 1997.

[2] Roskam, J.: Part VI: Preliminary Calculation of Aerodynamic, Thrust and Power Characteristcs. Lawrence, Kansas 66044, U.S.A.: 120 East 9th Street, Suite 2, DARcorporation, 2000.

[3] McCormick, W.: Aerodynamics, Aeronautics and Flight Mechanics. New York, Chichester, Brisbane, Toronto, Singapore, John Wiley \& Sons, 1979.

[4] Perkins, C. D., Hage, R. E.: Airplane Performance, Stability and Control. New York, John Wiley \& Sons, 1949.

[5] Coiro, D. P., Nicolosi, F.: "Aerodynamics, Dynamics and Performance Prediction of Sailplanes and Light Aircraft.” Technical Soaring, Vol. 24, No. 2, April 2000.
Prof. D. P. Coiro

phone: +39081 7683322

fax: +39081624609

e-mail: coiro@unina.it

Dr. A. De Marco

e-mail: agodemar@unina.it

Dr. F. Nicolosi

e-mail: fabrnico@unina.it

Dr. N. Genito

e-mail: nigenito@unina.it

Dr. S. Figliolia

e-mail: jdrfig@tin.it

Dipartimento di Progetazione Aeronautica (DPA)

University of Naples "Federico II"

Via Claudio 21

80125 Naples, Italy 